\title{
Do vendors benefit from promotions in a multi-vendor loyalty program?
}

\author{
Matilda Dorotic • Dennis Fok • Peter C. Verhoef • \\ Tammo H. A. Bijmolt
}

Published online: 3 November 2010

(C) The Author(s) 2010. This article is published with open access at Springerlink.com

\begin{abstract}
The growing trend of networking in recent years has led to an increase in number of loyalty program partnerships, most notably multi-vendor loyalty programs (MVLP). In an MVLP (as in other types of LPs), cardholders frequently receive promotional mailings intended to increase sales at the participating vendors. This study examines individual vendor and joint (multiple vendors) promotions on the sales performance of five main vendors within an MVLP. Findings of the study indicate low responsiveness of cardholders to LP-induced promotions. The responsiveness may be improved if multiple communication channels are used jointly to present an individual-vendor promotion. Moreover, this is one of the first empirical studies to investigate potential networking benefits of coalitions in an MVLP. Empirical evidence of coalition benefits of promotions is lacking, because we find neither stronger effects for joint-relative to individual promotions nor significant spillover effects of promotions across vendors (i.e., cross-vendor effects). The current study offers potential explanations for these findings.
\end{abstract}

Keywords Loyalty programs $\cdot$ Multi-vendor loyalty program $\cdot$ Promotion effectiveness $\cdot$ Joint promotions $\cdot$ Cross-vendor effects

M. Dorotic $(\bowtie) \cdot$ P. C. Verhoef • T. H. A. Bijmolt

Marketing Department, Faculty of Economics and Business,

University of Groningen, P.O. Box 800, NL-9700 AVGroningen, The Netherlands

e-mail: m.dorotic@rug.nl

M. Dorotic

e-mail: matilda.dorotic@efst.hr

M. Dorotic

Marketing Department, Faculty of Economics,

University of Split, Matice hrvatske 31, 21000 Split, Croatia

D. Fok

Erasmus School of Economics,

Erasmus University Rotterdam, P.O. Box 1738, 3000 DR Rotterdam, The Netherlands 


\section{Introduction}

In Western economies, more than $80 \%$ of adults participate in a loyalty program (LP), and oftentimes in multiple, competing LPs (Clark 2008; Consumer Reports 2008). The LP membership of U.S. consumers reached 1.8 billion in 2008, where cardholders on average are enrolled in more than 14 LPs, but remain active only in six of those (Ferguson and Hlavinka 2009). The main issue for LP managers is therefore retention and the engagement of existing cardholders rather than striving to enroll more cardholders. However, limited evidence exists on how to engage customers once they have become LP cardholders, which has resulted in calls for more research in this area (Grewal and Levy 2007).

Personalized marketing communication through promotions targeted at cardholders can be used to encourage cardholders' engagement (Kumar and Reinartz 2006; Kemp 2006; Blattberg et al. 2008). Promotions of LPs typically aim to increase the frequency and volume of purchases by rewarding cardholders with additional loyalty points or discounts over a limited time period. Still, more research is needed on the effects of LP-related promotions (Grewal and Levy 2007; Hardesty and Bearden 2009).

Program participation may be further encouraged in an LP offered by a coalition of multiple vendors, as such LPs tend to have greater perceived value (Capizzi and Ferguson 2005; Berman 2006). A specific form of such an LP includes a coalition of companies; with a specialized operator independent of the coalition partners that manages the LP (Blattberg et al. 2008: 578). Such coalitions are known as coalition LPS or multi-vendor LPs (MVLPs). Typically, they comprise partnerships of noncompeting firms, usually in frequently purchased sectors (e.g., grocery, fuel, apparel, credit card services). Nectar, Air Miles, FlyBuys, and Payback are prominent examples of MVLPs around the world.

Because LP cardholders obtain loyalty rewards for purchases with each partner in the coalition, MVLPs provide cardholders with advantages of convenience, faster point collection, and more redemption options. MVLPs allow vendors to expand their markets, which increases firm profitability (Kopalle and Neslin 2003; Liu and Yang 2009), particularly when the different businesses are complementary. In addition, the coalition may provide strategic benefits through spillover effects of vendors' images and cross-selling opportunities (Varadarajan 1986; Lemon and von Wangenheim 2009). In particular, a joint presentation of vendors' promotions in an MVLP may increase the efficiency and effectiveness of promotions. Furthermore, having one card for purchases at multiple vendors may encourage cardholders to patronize vendors that belong to a coalition and use promotions at MVLP partners to collect loyalty rewards more quickly (Berman 2006). So far, little research has investigated coalition benefits across vendors in an MVLP.

In analyzing longitudinal data of five prominent retailers in an MVLP, this study addresses two main research objectives. First, we aim to investigate the effects of LP-related promotions on a focal vendor's sales in diverse retailing sectors. Second, we study the existence of coalition benefits in the MVLP. This is among the first studies to investigate joint promotion and cross-vendor effects in a typical MVLP. 


\section{Theoretical background}

\subsection{Effects of LP-related promotions}

In this study, we differentiate between $L P$ rewards and LP-related promotions. The character of LP rewards is determined by LP design and dependent on accumulated purchases (as in the typical example of buy-X-get-one-free LP rewards). Conversely, LP-related promotions are short-term promotional actions targeted at LP cardholders, who cannot foresee promotions. In general, LP promotions aim to temporarily increase a member's usage of the LP by increasing LP patronage and spending. Typically, LPrelated promotions award LP cardholders with additional LP currency for purchases in one or more product categories during a promotional period. The additional amount of loyalty points is added to the regular amounts of points that could be collected on purchases in nonpromotional periods (e.g., double points on purchases during a promotional period). Such LP-related promotions differ from the "classic" notion of sales promotions: they are not price promotions, but essentially promotions related to the LP currency (loyalty points) and directed at collecting behavior.

Little is known about the effectiveness of LP-related promotions, particularly about their effects over time. Related studies on LP design primarily assessed the attractiveness of different types of reward incentives, ignoring the effects of shortterm promotions in LPs (Kim et al. 2001; Kivetz 2005; Keh and Lee 2006). In general, the design of LP incentives significantly influences program enrollment and usage (van Osselaer et al. 2004; Leenheer et al. 2007; Demoulin and Zidda 2009). However, LP participation delivers mainly long-term benefits through delayed rewards that cardholders can obtain for continuous purchases. Therefore, short-term promotions can help leverage a firm's short-term goals and encourage cardholders' engagement in LPs (Lewis 2004; Nunes and Dreze 2006b). Simulations by Lewis (2004) indicate that e-mailing an additional coupon (short-term promotion) increases cardholders purchase incidence rate, spending volume, and average customer revenue compared with offering only LP rewards.

However, LP rewards and LP-related promotions may increase cardholders' sensitivity to incentives, which may divert attention away from the brand and/or firm. The consequence is that the reward may become the primary reinforcement in purchases, which increases customers' spurious loyalty behavior (Rothschild and Gaidis 1981; Dowling and Uncles 1997; Roehm et al. 2002). This effect may be particularly pronounced in MVLPs, because of a possible incongruence of LP benefits with the focal products and a division of loyalty across vendors (Dowling and Uncles 1997; Kivetz 2005).

The effect of an LP-related promotion on sales may depend on the volume (number of cardholders receiving the promotion), the communication channel used (usually e-mail or post), or the number of featured vendors (individual versus joint promotions). An effect of the volume of a promotion is obvious: larger-volume promotions make offers salient to larger numbers of cardholders, which should have a direct, positive impact on effectiveness of the promotion. Direct mail and e-mail are the communication channels MVLPs use most frequently (Precision Marketing 2005; Kemp 2006). The integrated marketing communication literature advocates greater effectiveness from integrating multiple communication channels (Schultz 
1996; Naik and Raman 2003). This indicates that using multiple media to reach cardholders with the same promotion might be more effective than using only one medium. Finally, the effectiveness of individual relative to joint promotions is closely related to the coalition benefits, which we discuss next.

\subsection{Coalition benefits in multi-vendor loyalty programs}

Coalition benefits are particularly important for MVLPs, as they may provide significant benefits to participating vendors and an impulse for consumers to join the program. In particular, the MVLP's promotions may benefit from the coalition in two ways. First, promotions run jointly by multiple firms in the MVLP may have a greater effect than individual promotions. Second, cross-vendor effects on performance of other vendors in the MVLP may occur with the promotions of one vendor in the program.

Debate exists in the literature on the effectiveness of the joint relative to individual presentation of sales promotions (Simonin and Ruth 1998; Geylani et al. 2008). Because joint offers feature several promotions across different partners, they may induce positive coalition effects through reinforcement of brand images and an increase in perceived value (Varadarajan and Rajaratnam 1986). In contrast, the joint presentation of vendors increases the transparency of incentives across vendors, which may foster comparison and strengthen the importance of incentives rather than products (Rothschild and Gaidis 1981; Dowling and Uncles 1997).

An MVLP promotion that features one vendor in a coalition makes the MVLP itself more salient, which could be beneficial to other partners in the coalition (Bucklin and Sengupta 1993; Simonin and Ruth 1998). Hence, individual promotions of one vendor may affect sales at other vendors through spillover effects of MVLP-related promotions. We refer to this form of coalition benefits cross-vendor effects of LP-related promotions. Another rationale for the potential of cross-vendor effects is that the promotions may induce faster collection of points, which may encourage cardholders to earn more points by purchasing at multiple vendors in the coalition (Sharp and Sharp 1997; Kivetz et al. 2006; Nunes and Dreze 2006b).

\section{Methodology}

\subsection{Data description}

To empirically assess own- and cross-vendor effects of sales promotions in an MVLP, we analyze data from a renowned MVLP in the Netherlands. This program spans retailers from various sectors (e.g., department stores, grocery, and fuel retailing, apparel retailing, drug stores, liquor stores, do-it-yourself, electronics). Cardholders collect loyalty points on their purchases at participating vendors. On average, for each euro spent, a member receives one loyalty point (although policies of some vendors varied over time). Customers can redeem collected points for various merchandise, entertainment, or travel arrangements. Data are available for the largest five vendors in the program, which together account for $91 \%$ of all promotions in the MVLP (see 
Table 1). All five vendors have strong brand equity in their respective sectors and are not direct competitors.

For each vendor, aggregate weekly data on performance is available for 141 weeks, from the beginning of year 2005 until mid-2007. To specify appropriate performance measures, we use the rationale that successful marketing promotions would lead to increases in customer spending (Van Heerde and Bijmolt 2005). A customer's spending level directly corresponds to the number of loyalty points obtained on his or her purchase. Therefore, the number of loyalty points issued in a certain week can be used as a measure of a vendor's performance. Panel unit root tests show that (the log of) this performance measure is stationary over time, as the $p$ values corresponding to the Levin et al. (2002) statistic and the Im et al. (2003) W statistic are indistinguishable from zero.

The MVLP operator sends sales promotion mailings to cardholders with offers of the program's vendors (similar to an example in Kemp 2006). These LP-related promotions offer cardholders an additional amount of points for purchases in a certain category during a limited time period. To allow for a comparison of promotional and nonpromotional periods, we do not include this additional amount of loyalty points in our performance measure. The resultant dependent variable is the number of (regular) loyalty points issued by each vendor.

The promotions differ in volume, duration, communication channel, and number of vendors featured. The volume of a promotion refers to the number of cardholders receiving the mailing with the promotion. Using a median split per vendor, the promotions were grouped into large-volume and small-volume promotions. The promotion duration differed substantially both within and across vendors. Some promotions lasted only for 1 week, and a few promotions spanned more than 10 weeks, with 18 weeks being the longest duration of a promotion. As for the utilized communication channel, vendors may use e-mail, direct mail, or a combination of those. Finally, mailings may feature promotions of a single vendor (individual promotions) or promotions of more than one vendor (joint promotions).

Table 1 presents some descriptive statistics across vendors in the analyzed database. The table shows that our data spans in total 185 promotions, of which 127 were individual promotions and 58 were joint promotions. The total number of

Table 1 Descriptive statistics of promotions and vendors

\begin{tabular}{llllll}
\hline Vendor & $\begin{array}{l}\text { Retail } \\
\text { sector }\end{array}$ & $\begin{array}{l}\text { No. of individual } \\
\text { promotions }\end{array}$ & $\begin{array}{l}\text { No. of joint } \\
\text { promotions }\end{array}$ & $\begin{array}{l}\text { Most frequent promotion } \\
\text { duration (weeks) }\end{array}$ & $\begin{array}{l}\text { Most frequent } \\
\text { medium }\end{array}$ \\
\hline 1 & Grocery & 2 & 4 & $2-3$ & E-mail \\
2 & Electronics & n.a. & 16 & $2-4$ & E-mail \\
3 & DIY & 35 & 16 & 2 & Post \\
4 & Fuel & 46 & 16 & $8-9$ & Post \\
5 & Department & 44 & 6 & 1 & E-mail+Post \\
\hline
\end{tabular}

n.a. vendor did not have individual promotions in the observation period 
promotions running at the same time in a week ranges from 0 to a maximum of nine promotions (individual and joint promotions of all MVLP vendors), with an average of 3.7 promotions. Furthermore, there are differences in the promotions the vendors used. Note that in this study, we are mainly interested in general patterns and effect sizes, but we allow for vendor-specific effects in our modeling approach.

\subsection{Model}

\subsubsection{Effects of LP-related promotions}

To model changes in vendor $j$ 's sales to cardholders in week $t$, we analyze the number of loyalty points issued by vendor $j$ in week $t\left(\mathrm{LP}_{j t}\right)$. The logarithmic transformation of the dependent variable $\left(\operatorname{lnLP}_{j t}\right)$ facilitates comparison of effect sizes across vendors. Note that effect sizes should, in this case, be interpreted in percentage terms. Our model relates $\operatorname{lnLP}_{j t}$ to the vendor's baseline performance, to the vendor's individual promotion(s) in this period, to the vendor's joint promotion (s), and to the promotion(s) of other vendors in the program in the same period.

A sales promotion may last for several weeks. Hence, it is important to account for possibly declining effects over time. The effect of a promotional mailing is expected to decrease over time because of forgetting and because there is a limit to how much a consumer can consume in response to a promotion (Blattberg et al. 1995). We, therefore, specify an exponential decay function for the effect of the time that has passed since the beginning of the promotion.

\subsubsection{Own effects and coalition benefits}

Individual and joint promotions of vendor $j$ and cross-vendor effects of promotions of other vendors $(s \neq j)$ in the MVLP may affect changes in the number of loyalty points vendor $j$ issues in week $t$. The individual promotions of vendor $j$ are denoted by $\mathrm{IM}_{k j t}, k=1, \ldots, K_{j} . \mathrm{IM}_{k j t}=1$ if the $k$ th individual promotion by vendor $j$ is valid in week $t$; otherwise, $\mathrm{IM}_{k j t}$ equals $0 . K_{j}$ is the total number of individual promotions of vendor $j$ in the observation period. The mailings with joint promotions that feature vendor $j$ (among promotions of other vendors) are denoted by $\mathrm{JM}_{i j t}$, with equivalent specifications as for individual promotions. We specify the following model for the number of points issued:

$$
\ln \mathrm{LP}_{j t}=\alpha_{j}+\sum_{k=1}^{K_{j}} \beta_{k j t} \mathrm{IM}_{k j t}+\sum_{i=1}^{I_{j}} \varphi_{i j t} \mathrm{JM}_{i j t}+\sum_{s \neq j} \sum_{k=1}^{K_{s}} \delta_{k s t} \mathrm{IM}_{k s t}+Z_{j t}{ }^{\prime} \tau_{j}+\varepsilon_{j t} .
$$

where $\alpha_{j}$ denotes the baseline performance for vendor $j$ in terms of points issued, $\beta_{k j t}$ gives the effect of individual promotion $k$ by vendor $j$ in week $t, \varphi_{i j t}$ gives the effect of joint promotion $i$, and $\delta_{k s t}$ denotes the cross-vendor effect of the $k$ th promotion by vendor $s(s \neq j)$ in week $t$ on the performance of vendor $j$. Because it is possible to have more than one promotion in a given week, the effects of all promotions are summed across all available promotions in week $t$, for own as well as for crossvendor effects within the LP. The indicator variables $\mathrm{IM}_{k j t}, \mathrm{JM}_{i j t}$, and $\mathrm{IM}_{k s t}$ ascertain that the appropriate promotions are selected in Eq. 1. The effects of promotions are 
specified to depend on time $t$ and on the specific promotion $k$ or $i$. We discuss this dependence in detail in the next subsection.

The effects of individual and joint promotions of vendor $j$ on its performance create the own effects of sales promotions $\left(\beta_{k j t}\right.$ and $\left.\varphi_{i j t}\right)$. Because vendor $j$ belongs to the coalition in the MVLP, coalition benefits may occur as a result of synergies in the coalition. The coalition benefits in the MVLP could be identified by the greater effectiveness of joint relative to individual-vendor promotions $\left(\varphi_{i j t}>\beta_{k j t}\right)$ and/or positive cross-vendor effects $\left(\delta_{k s t}>0\right)$.

Equation 1 also contains the vector $Z_{j t}$, which encompasses a number of additional regressors. First, because some vendors changed their policy of issuing loyalty points to the cardholders, dummy variables for this policy change are included for these specific vendors. For example, one vendor decided to reduce the number of loyalty points offered per euro spent (before the policy change, a vendor offered one loyalty point for every euro spent; after the change, the vendor offered one loyalty point for every two euros spent). The corresponding dummy is zero initially and becomes one after the policy change. ${ }^{1}$ Second, the performance of some vendors is subject to seasonal variation. For those vendors, seasonal adjustment dummies are included in $Z_{j t}$. The seasonality in these cases corresponds to potential seasonal peaks in sales before holidays or seasonal clear-outs (e.g., Christmas, Easter) and potential seasonal dips in sales during holiday weeks. The appropriate seasonal factors to use were selected on a vendor-by-vendor basis. Finally, $\varepsilon_{j t}$ gives the error term for vendor $j$ in week $t$. We discuss the exact specification of this error term in a later subsection.

\subsubsection{Moderating effects on promotion effectiveness}

The effect of promotion $k$ by vendor $j$ in week $t$ may depend on the duration of that promotion (time since issuance) and on other idiosyncrasies of a particular promotion (e.g., volume, communication channel). Therefore, the own effect of promotion $k$ by vendor $j$ at time $t$ on the number of loyalty points is specified as follows:

$$
\beta_{k j t}=\left(e^{\gamma_{1} T_{k j t}}\right)\left(\theta_{j}+\gamma_{2} \mathrm{LV}_{k j}+\gamma_{3} \mathrm{MP}_{k j}+\gamma_{4} \mathrm{MEP}_{k j}\right) .
$$

The first part of the right-hand side in Eq. 2 indicates the effect of time. $T_{k j t}$ is the number of weeks passed since the beginning of promotion $k$ by vendor $j$ in week $t$ $\left(T_{k j t}=0,1,2, \ldots\right)$. The corresponding parameter $\left(\gamma_{1}<0\right)$ gives the decay rate. The exponential decay function together with $\gamma_{1}<0$ implies that the duration effect proportionally declines over time and therefore does not change sign.

The three variables on the right-hand side of Eq. 2 are dummy variables indicating whether the promotion is of a specific size and medium. The corresponding parameters are $\gamma_{2}, \ldots, \gamma_{4}$. The dummy variables are specified as follows:

$\mathrm{LV}_{k j} \quad$ Promotion $k$ by vendor $j$ has a large volume (larger than median promotion of the same vendor).

$\mathrm{MP}_{k j} \quad$ Promotion $k$ by vendor $j$ uses the post-only medium.

$\mathrm{MEP}_{k j}$ Promotion $k$ by vendor $j$ uses both post and e-mail.

\footnotetext{
${ }^{1}$ Note that the points ratio per se is not problematic, as a log transformation of the dependent variable is used. As long as the ratio is constant over time, it will be absorbed in the equation's constant. In cases when the points ratio per vendor changes over time, we introduced policy change variables.
} 
The parameter $\theta_{j}$ denotes a vendor-specific effect. This vendor-specific effect captures possible differences in the promotion effects across vendors (e.g., due to differences in brand equity across vendors). The effects of the abovementioned characteristics of a promotion are all relative to this vendor-specific effect. The parameter $\theta_{j}$ can also be interpreted as a benchmark effect for vendor $j$. In the case that all promotion dummies are zero, Eq. 2 implies that the effect of the promotion in the first week equals $\theta_{j}$. This setting for the dummy variables corresponds with small promotions that are sent via e-mail. As we are primarily interested in overall effects of the MVLP (rather than particular effects of one promotion on one vendor), we restrict the coefficients of the dummies across vendors.

The effects of joint promotions are specified analogous to Eq. 2, with the difference that no joint promotions were sent only through post, so the effects of e-mail and combined channels are assessed for joint promotions. Because this specification is analogous we do not state the exact equation here.

In line with the effects of promotions of the vendor itself, for the cross-vendor effect of promotion $k$ by vendor $s$ at time $t$ on the performance of vendor $j$, we specify the following:

$$
\delta_{k s t}=\left(e^{\gamma_{1} T_{k s t}}\right)\left(\omega_{s}+\pi_{2} \mathrm{LV}_{k s}+\pi_{3} \mathrm{MP}_{k s}+\pi_{4} \mathrm{MEP}_{k s}\right) .
$$

Although we allow for a different impact of the promotion characteristics, for reasons of parsimony, we impose the same decay rate as for the own effects.

\subsubsection{Full model}

To deal with possible autocorrelation, we explicitly allow for serial correlation in the error terms. We specify autoregressive processes of order 1 [AR(1)] for the error term as follows:

$$
\varepsilon_{j t}=\rho_{j} \varepsilon_{j t-1}+\varepsilon_{j t}^{*}
$$

The error term $\varepsilon_{j t}^{*}$ is assumed to be independent and identically distributed. The combination of Eqs. 1 and 4 gives a model that appropriately deals with autocorrelation without affecting the interpretation of the original parameters. Combining specified Eqs. 1 and 4 gives:

$$
\begin{aligned}
\ln \mathrm{LP}_{j t}=\alpha_{j} & +\sum_{k=1}^{K_{j}} \beta_{k j t} \mathrm{IM}_{k j t}+\sum_{i=1}^{I_{j}} \varphi_{i j t} \mathrm{JM}_{i j t}+\sum_{s \neq j} \sum_{k=1}^{K_{s}} \delta_{k s t} \mathrm{IM}_{k s t}+Z_{j t}{ }^{\prime} \tau_{j} \\
& +\rho_{j}\left(\ln \mathrm{LP}_{j t-1}-\alpha_{j}-\sum_{k=1}^{K_{j}} \beta_{k j t-1} \mathrm{IM}_{k j t-1}-\sum_{i=1}^{I_{j}} \varphi_{i j t-1} \mathrm{JM}_{i j t-1}+\sum_{s \neq j} \sum_{k=1}^{K_{s}} \delta_{k s t-1} \mathrm{IM}_{k s t-1}+Z_{j t-1}{ }^{\prime} \tau_{j}\right) \\
& +\varepsilon_{j t}^{*}
\end{aligned}
$$

For estimation purposes, we combine Eq. 5 with the definitions of the effect sizes, as given in Eqs. 2 and 3 for the points issued. The result is a system of equations (seemingly unrelated regressions (SUR)) estimated using iterated feasible generalized least squares (Zellner 1962). 


\section{Results}

\subsection{Effects of vendor's sales promotions on spending patterns}

For most of the five vendors, we found that analyzed LP promotions do not have a significant impact on aggregate sales to cardholders, that is, on the number of loyalty points issued (see Tables 2 and 4). The benchmark promotions (small, direct sales promotions sent by e-mail) have a significant impact on the performance measure only for the department store (vendor 5). This may suggest that retailers with relatively larger assortment benefit more from own direct sales promotions in the MVLP.

Moreover, the results in Table 2 show that the effectiveness of a vendor's own promotions does not differ significantly with volume of promotion. Largevolume promotions do not have a significant greater effect than smaller-volume promotions. The only significant effect of promotions we found was for promotions that used multiple communication channels. Using an integrated communication through e-mail and post (direct mailing) gives a significantly larger effect of promotions on the number of loyalty points issued. Across the analyzed vendors, joint usage of the e-mail and post in individual sales promotions increases the effect on the number of loyalty points issued in the first week of a promotion by about 13 percentage points. This effect cannot be attributed to a larger part of the cardholders being reached with multiple channels, as we explicitly correct for the volume of the promotion. However, the same effect is not present in joint

Table 2 Effects of individual versus joint promotions on vendors' performance

Log number of loyalty points issued

\begin{tabular}{|c|c|c|c|c|}
\hline \multirow[t]{2}{*}{ Explanatory variables } & \multicolumn{2}{|c|}{ Individual promotions } & \multicolumn{2}{|c|}{ Joint promotions } \\
\hline & Est. & $t$ value & Est. & $t$ value \\
\hline Decay rate & -5.850 & -0.027 & -5.850 & -0.027 \\
\hline Benchmark for grocery retailer & -0.010 & -0.322 & -0.014 & -0.437 \\
\hline Benchmark for electronics retailer & n.a. & n.a. & 0.033 & 0.652 \\
\hline Benchmark for DIY retailer & 0.001 & 0.025 & 0.011 & 0.364 \\
\hline Benchmark for fuel retailer & -0.023 & -1.370 & -0.0004 & -0.025 \\
\hline Benchmark for department stores & $0.214 *$ & 3.629 & 0.054 & 0.550 \\
\hline Large volume & 0.021 & 1.518 & -0.025 & -1.056 \\
\hline Post only & 0.016 & 1.008 & n.a. & n.a. \\
\hline Email+post & $0.129 *$ & 2.468 & 0.038 & 1.450 \\
\hline
\end{tabular}

The decay rate is restricted to be equal for individual and joint promotions

n.a. Vendor did not use the selected category in the observed period

$* p<0.01$ 
promotions. The decay rate indicates decreasing effectiveness (contribution) of a promotion over time (Table 2$)^{2}$

For example, Fig. 1 illustrates the contributions of different communication channels for vendor 5. The effect of sales promotions that used e-mail and post (e-mail and post series) is considerably greater than the effect of promotions using only post (the post-only series) or only e-mail (the e-mail-only [benchmark] series). However, the effects of a promotion decline rapidly after the issuance week and die out by the second week.

Table 3 shows the impact of the adjustment variables as well as the adjusted $R^{2}$ per equation. The results show a satisfactory explanatory power of the individual equations in the model. Interestingly, only very substantial changes in issuance policies (e.g., giving half a loyalty point per euro spent) have a significant (negative) impact on vendors' issuance of loyalty points. Vendors 3 and 4, which introduced less drastic policy changes, did not experience negative effects on their approximated sales. Jointly, the results indicate overall habitual (inertia) behavior of existing cardholders, who tend to follow their regular purchase patterns.

\subsection{Coalition benefits in multi-vendor loyalty programs}

The analysis shows no evidence of coalition benefits in the MVLP. If coalition synergies would occur, then across all vendors, joint promotions should have a significant impact on members' spending patterns, and this impact should be greater than the impact of individual promotions. The comparison of the results for individual and joint promotions in Table 2 indicates that joint promotions are less effective than promotions that feature solely the focal vendor (individual promotions). Moreover, there are no significant cross-vendor effects of promotions of coalition partners on the performance of the focal vendor (see Table 4). It seems that neither volume nor communication channel significantly affects cross-vendor effects of promotions of other vendors in the coalition on the performance of focal vendor (in Table 4).

\section{Robustness checks}

Because the finding of insignificant effects of LP-related promotions may seem surprising, we conducted several additional analyses to check the robustness of the findings.

First, to account for the potential effects of the value of a promotion, we consider a model that uses an approximation of the promotion value instead of a dummy variable for $\mathrm{IM}_{k j t}, \mathrm{JM}_{i j t}$, and $\mathrm{IM}_{k s t}$ in Eq. 5. The value of a promotion is approximated by how many more additional points a cardholder obtains in the promotion relative to nonpromotional periods. For example, if a promotion offers

\footnotetext{
${ }^{2}$ The fact that the estimated decay parameter is quite large but not significantly different from zero may be counterintuitive. The decay rate of -5.8 implies that there is only a direct effect. Note that $\exp (-5.8 \times t)$ equals 1 for $t=0$ and approximately 0 for $t=1,2,3 \ldots$. Because of the exponential transformation, the function of the (generalized) sum of squared errors in the SUR procedure is almost flat in this region of the decay rate. This results in a relatively large standard error and a small $t$ value for this decay rate.
} 


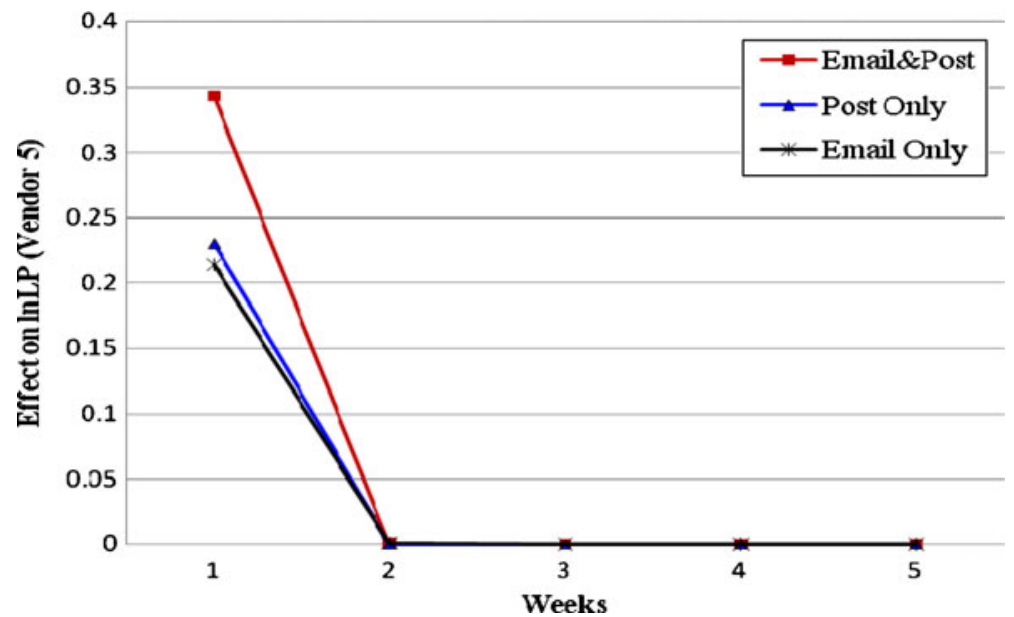

Fig. 1 Effects of different communication channels on the loyalty points issued over time (an example for vendor 5, small promotions)

100 additional points for spending ten euros at some vendor (and the points ratio is one point for each euro spent), then the promotion offers ten times more points than the cardholder would obtain otherwise. Promotion values ranged from two to 30 times more points and differed across vendors. In the new estimations, we used the natural logarithm of the approximated value of the promotion instead of the promotional dummies. As the value approximation is not always straightforward, and for some promotions the complete information is lacking, we report the original findings as the main results and briefly report the findings of this additional analysis. Overall, estimations in this specification give full support to the original results (ruling out the lack of variation as a possible methodological bias). Again, only the benchmark for department stores had a significant effect on the number of issued points (coefficient $=0.115, t=4.85$ ). Although of the right sign, the effect of e-mail and post is not significant at the $95 \%$ significance level (coefficient $=0.026, t=1.488$ ) in this specification. This is due to the previously explained difficulties in value approximation.

Table 3 Vendor-specific adjustment effects and explained variance

\begin{tabular}{|c|c|c|c|c|c|}
\hline \multirow[t]{2}{*}{ Vendor/variable } & \multicolumn{5}{|c|}{ Log number of loyalty points } \\
\hline & V1 & $\mathrm{V} 2$ & V3 & V4 & V5 \\
\hline Policy change & n.a. & $-0.53 *$ & -0.04 & -0.03 & $-0.83 *$ \\
\hline Seasonal peaks & $0.21 *$ & $0.61 *$ & $0.25 *$ & n.a. & $1.03 *$ \\
\hline Seasonal dips & $-0.09 *$ & n.a. & $-0.32 *$ & -0.12 & $-2.97 *$ \\
\hline Autocorrelation $\rho$ & $0.68^{*}$ & $0.28^{*}$ & $0.45^{*}$ & $0.73 *$ & $0.37 *$ \\
\hline Adjusted $R^{2}$ & 0.62 & 0.63 & 0.49 & 0.62 & 0.81 \\
\hline
\end{tabular}

$* p<0.01$

n.a. Not applicable 
Table 4 Cross-vendor effects of individual promotions

\begin{tabular}{lcc}
\hline Cross-vendor effects & Log number of loyalty points & \\
\hline Explanatory variable & Estimate & $t$ value \\
Benchmark for grocery retailer & -0.023 & -0.852 \\
Benchmark for electronics retailer & n.a. & n.a. \\
Benchmark for DIY retailer & -0.008 & -0.567 \\
Benchmark for fuel retailer & 0.003 & 0.226 \\
Benchmark for department stores & 0.008 & 0.597 \\
Large volume & 0.006 & 0.631 \\
Post only & 0.003 & 0.221 \\
Email+post & -0.008 & -0.533 \\
\hline
\end{tabular}

n.a. Vendor did not have individual promotions in the observed period

Second, joint promotions may differ with respect to the number of participating vendors. To account for this explanation, we included the number of participating vendors as an additional explanatory variable. The number of vendors that participated in a joint action does not have a significant effect on the number of collected points (coefficient $=-0.001, t=-0.458$ ).

Finally, although promotions may not affect spending levels of cardholders, they may attract more cardholders to stores. Therefore, we conducted the same set of analyses on the natural logarithm of the (weekly) aggregate number of cardholders attracted to stores of analyzed vendors. The estimations showed the same substantive results of insignificant effects of LP-related promotions and the lack of spillover effects across vendors. ${ }^{3}$

\section{Discussion}

The findings of this study indicate that, in general, vendors' sales promotions in an MVLP do not change the aggregate patterns of cardholders' purchase behavior. That is, MVLP cardholders use their cards in regular purchases and collect loyalty rewards for them. However, they generally do not change their purchase behavior to respond to LP promotions. Indeed, Leenheer et al. (2007) found that neither the discount nor the savings feature of LPs significantly affect cardholders' behavior once they are enrolled in an LP. We emphasize here that our findings do not indicate the lower effectiveness of MVLP relative to LPs of a single vendor, as we do not possess the data to compare the effects across diverse LP types. Keeping that in mind, we further explore possible explanations for the obtained results. The lack of significant impact on cardholders' behavior may be due to a low perceived value of promotions (Nunes and Dreze 2006a; Consumer Reports 2008). If customers do not particularly value a promotion, then the promotion will not induce customers to

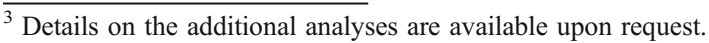


change their usual patterns of behavior in response to the promotion. The most common direct sales promotions in LPs feature additional loyalty point promotions, in which, for example, cardholders may obtain 300 additional loyalty points for 30 euros spent at the focal vendor. Such a promotional offer may not provide sufficient value to make cardholders purchase more than planned or to attract cardholders who do not usually purchase at the focal vendor. This may be especially true for purchases of fuel, electronics, or do-it-yourself goods.

Furthermore, two other underlying mechanisms may provide substantive bases for understanding the findings. ${ }^{4}$ The first potential explanation is the awareness and ease with which cardholders can translate the obtained points into euros and/or purchase outcomes. A recent study by Kwong et al. (2010) showed that the decision to spend LP points depends on the computational ease of translating points to a monetary equivalent. The second related explanation is perceived effort (i.e., inconvenience and thinking costs) of redeeming points. To explore these issues, we analyzed cardholders' responses to two surveys that the MVLP administered in 2007 and 2008 (sample sizes 274 and 1,392, respectively). Remarkably, the surveys revealed that loyalty points may be a pallid currency in consumer minds because some consumers exert little effort in processing information about the LP (Kwong et al. 2010). On a question of what respondents think is the value of one loyalty point (in euros), $43.5 \%$ of respondents $(N=1,392)$ were unaware of the exact points-ratio value and chose a "wrong" answer among several offered amounts (which differed substantially and ranged from 0.01 eurocent to more than one euro). There are probably several reasons for such a lack of engagement. First, additional insights from the MVLP provider indicate that cardholders seem to be overall little engaged with the LP, and only increase the engagement at reward redemption. Another reason for the lack of engagement can be a high perceived effort and/or inconvenience to obtain benefits of the analyzed promotions. Namely, the additional points are not awarded automatically to a cardholder at a point of purchase; instead, the cardholder has to print out a coupon beforehand from the Internet or obtain it through post. Although this practice is used to increase engagement of cardholders with the MVLP, the required effort may diminish the effectiveness of promotions. In a survey of 274 cardholders, respondents indicated that they would prefer direct discounts to promotional offers of additional loyalty points (only $12.8 \%$ of respondents chose additional points as the preferred type of promotion).

We do, however, find that the effectiveness of individual promotions in the MVLP is enhanced if multiple communication channels are used jointly to present a promotion. In this way, we find support for the effectiveness of integrated marketing communication (Schultz 1996; Naik and Raman 2003). This finding suggests that, in cases when cardholders are not prone to exert effort in processing information and requirements of an LP, joint types of media may be more effective at encouraging response.

A particularly important dimension of MVLPs concerns coalition benefits between program partners. Our findings show no empirical support for the existence

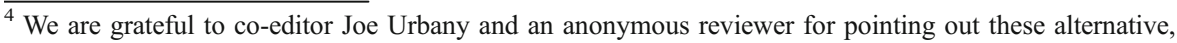
substantive explanations.
} 
of significant coalition benefits among vendors in an MVLP. Joint promotions that feature offers of several vendors in the coalition are relatively less effective than promotions that feature individual vendors. The reason may be that instead of reinforcing the usage of the program at several vendors to collect points faster, joint offers promote comparison across deals and a division of purchases across vendors (Dowling and Uncles 1997). In addition, the cross-vendor effects are not substantial. Given the limited effectiveness of marketing promotions on own performance measures, the insignificance of cross-vendor effects is to be expected, as crosseffects should be smaller than the own-promotion effects (Leeflang et al. 2008).

\section{Limitations and further research}

This study analyzed a single MVLP, and although its design and vendor types represent the typical multi-vendor scheme, replications of this study are needed to reach general conclusions. Because our data refer to only one MVLP, we have focused primarily on the promotional effects in the MVLP rather than on benefits of MVLPs themselves or their effectiveness relative to other types of LPs (e.g., singlevendor LPs). A preferred approach to analyzing the effectiveness of LP-related promotions (relative to other types of promotions) would be to compare the effects of individual promotions by each vendor outside of the MVLP (i.e., the effectiveness of non-LP-related promotions) with the effects of individual promotions in the MVLP. Furthermore, a clearer picture could be obtained with information on other marketing activities that focal vendors run simultaneously, like price promotions and other activities.

Moreover, the results of this study may be affected with the effectiveness of MVLP's management. The lack of cardholders' engagement may have diverse sources. It may be due to an ineffective communication or management of the MVLP, or because of the natural complexity of the LP concept and the pallid perceptions of the LP currency. We believe we have uncovered here some fertile ground for future research, particularly about the role of perceptions of LP currency and the conversion ratio between LP currency and monetary currency.

Furthermore, the analyzed MVLP runs promotions very frequently (on average more than three promotions a week). Cardholders may become weary of such hyperactive promotion activities, which may cause them to start ignoring the promotions. This may explain the lack of effects in the presented results. It is therefore crucial that future research would study different MVLPs. Comparing MVLPs might help in understanding the impact of the management of an MVLP on the impact of promotions' effectiveness in the MVLP.

Our database provided aggregate performance measures per vendor. Individual data on customer behavior would allow for important additional insights. First, we could not assess differences in behavior of LP cardholders versus nonmembers. The behavior of both groups of customers has important implications for vendors' performance (van Heerde and Bijmolt 2005). Second, aggregate measures cannot explain the heterogeneity that exists across cardholders in the MVLP. Finally, although we assessed the effectiveness of promotions, we cannot say anything about their efficiency because we lack cost data. 
Open Access This article is distributed under the terms of the Creative Commons Attribution Noncommercial License which permits any noncommercial use, distribution, and reproduction in any medium, provided the original author(s) and source are credited.

\section{References}

Berman, B. (2006). Developing an effective customer loyalty program. California Management Review, 49(1), 123-148.

Blattberg, R. C., Briesch, R., \& Fox, E. J. (1995). How promotions work. Marketing Science, 14(3), 122132 .

Blattberg, R. C., Kim, B. D., \& Neslin, S. A. (2008). Database marketing: Analyzing and managing customers. New York: Springer.

Bucklin, L. P., \& Sengupta, S. (1993). Organizing successful co-marketing alliances. Journal of Marketing, 57(2), 32-46.

Capizzi, M. T., \& Ferguson, R. (2005). Loyalty trends for the twenty-first century. Journal of Consumer Marketing, 22, 72-80.

Clark, N. (2008). Divided loyalties (cover story). Marketing, 00253650, 28-29.

Demoulin, N. T. M., \& Zidda, P. (2009). Drivers of customers' adoption and adoption timing of a new loyalty card in the grocery retail market. Journal of Retailing, 85, 391-405.

Dowling, G. R., \& Uncles, M. (1997). Do customer loyalty programs really work? Sloan Management Review, 38(4), 71-82.

Ferguson, R. \& Hlavinka, K. (2009). The Big Sort: The 2009 Colloquy Loyalty Marketing Census, in White Paper Series: Loyalty One/Colloquy.

Geylani, T., Inman, J. J., \& Ter Hofstede, F. (2008). Image reinforcement or impairment: The effects of cobranding on attribute uncertainty. Marketing Science, 27(4), 730-744.

Grewal, D., \& Levy, M. (2007). Retailing research: Past, present, and future. Journal of Retailing, 83(4), 447-464.

Hardesty, D.M. \& Bearden, W.O. (2009). Consumer Behavior and Retailing, Journal of Retailing, 239-244.

Im, K. S., Pesaran, M. H., \& Shin, Y. (2003). Testing for unit roots in heterogeneous panels. Journal of Econometrics, 115(1), 53-74.

Keh, H. T., \& Lee, Y. H. (2006). Do reward programs build loyalty for services? The moderating effect of satisfaction on type and timing of rewards. Journal of Retailing, 82(2), 127-136.

Kemp, E. (2006). Nectar targets mailings by purchasing behaviour. Marketing, 07(05/2006), 4-4.

Kim, B. D., Shi, M., \& Srinivasan, K. (2001). Reward programs and tacit collusion. Marketing Science, 20 (2), 99-120.

Kivetz, R. (2005). Promotion reactance: The role of effort-reward congruity. Journal of Consumer Research, 31(4), 725-736.

Kivetz, R., Urminsky, O., \& Zheng, Y. H. (2006). The goal-gradient hypothesis resurrected: Purchase acceleration, illusionary goal progress, and customer retention. Journal of Marketing Research, 43(1), 39-58.

Kopalle, P. K., \& Neslin, S. A. (2003). The economic viability of frequency reward programs in a strategic competitive environment. Review of Marketing Science, 1, 1-39.

Kumar, V. \& Reinartz, W. (2006). Customer relationship management: A Databased Approach: John Wiley \& Sons, Inc.

Kwong, J. Y.Y., Soman, D. \& Ho, C.K.Y. (2010). The role of computational ease on the decision to spend loyalty program points, Journal of Consumer Psychology, doi:10.1016/j.jcps.2010.08.005.

Leeflang, P. S. H., Selva, J. P., Van Dijk, A., \& Wittink, D. R. (2008). Decomposing the sales promotion bump accounting for cross-category effects. International Journal of Research in Marketing, 25(3), 201-214.

Leenheer, J., van Heerde, H. J., Bijmolt, T. H. A., \& Smidts, A. (2007). Do loyalty programs really enhance behavioral loyalty? An empirical analysis accounting for self-selecting members. International Journal of Research in Marketing, 24(1), 31-47.

Lemon, K. N., \& von Wangenheim, F. (2009). The reinforcing effects of loyalty program partnerships and core service usage a longitudinal analysis. Journal of Service Research, 11(4), 357-370.

Levin, A., Lin, C. F., \& Chu, C. S. J. (2002). Unit root tests in panel data: Asymptotic and finite-sample properties. Journal of Econometrics, 108(1), 1-24. 
Lewis, M. (2004). The influence of loyalty programs and short-term promotions on customer retention. Journal of Marketing Research, 41(3), 281-292.

Liu, Y., \& Yang, R. (2009). Competing loyalty programs: Impact of market saturation, market share, and category expandability. Journal of Marketing, 73(1), 93-108.

Marketing, P. (2005). Airmiles builds collector levels via direct drive. Precision Marketing, 17(18), 6-6.

Naik, P. A., \& Raman, K. (2003). Understanding the impact of synergy in multimedia communications. Journal of Marketing Research, 40(4), 375-388.

Nunes, J. C., \& Dreze, X. (2006a). Your loyalty program is betraying you. Harvard Business Review, 84 (4), 124-131.

Nunes, J. C., \& Dreze, X. (2006b). The endowed progress effect: How artificial advancement increases effort. Journal of Consumer Research, 32(4), 504-512.

Reports, C. (2008). Points mania. Consumer Reports, 73, 12-13.

Roehm, M. L., Pullins, E. B., \& Roehm, H. A. (2002). Designing loyalty-building programs for packaged goods brands. Journal of Marketing Research, 39(2), 202-213.

Rothschild, M. L., \& Gaidis, W. C. (1981). Behavioral learning-theory-its relevance to marketing and promotions. Journal of Marketing, 45(2), 70-78.

Schultz, D. E. (1996). The inevitability of integrated communications. Journal of Business Research, 37 (3), 139-146.

Sharp, B., \& Sharp, A. (1997). Loyalty programs and their impact on repeat-purchase loyalty patterns. International Journal of Research in Marketing, 14(5), 473-486.

Simonin, B. L., \& Ruth, J. A. (1998). Is a company known by the company it keeps? Assessing the spillover effects of brand alliances on consumer brand attitudes. Journal of Marketing Research, 35 (1), 30-42.

Van Heerde, H. J., \& Bijmolt, T. H. A. (2005). Decomposing the promotional revenue bump for loyalty program members versus nonmembers. Journal of Marketing Research, 42(4), 443-457.

van Osselaer, S. M. J., Alba, J. W., \& Manchanda, P. (2004). Irrelevant information and mediated intertemporal choice. Journal of Consumer Psychology, 14(3), 257-270.

Varadarajan, P. R. (1986). Horizontal cooperative sales promotion-a framework for classification and additional perspectives. Journal of Marketing, 50(2), 61-73.

Varadarajan, P. R., \& Rajaratnam, D. (1986). Symbiotic marketing revisited. Journal of Marketing, 50(1), $7-17$.

Zellner, A. (1962). An efficient method of estimating seemingly unrelated regressions and tests for aggregation bias. Journal of the American Statistical Association, 57(298), 348-368. 